\title{
Effectiveness of Appraisal of Public Records in Tanzania: Findings from President's Office Records and Archives Management Department (PO-RAMD)
}

\author{
Lameck Sospeter Kashaija \\ Tanzania Public Service College, P.O box 1534, Singida Tanzania
}

\begin{abstract}
This article discusses the effectiveness of appraisal of public records in Tanzania. It addresses the ineffectiveness of public records appraisal in various offices in Tanzania and come up with the best approaches for the exercise on regard of the country guidelines, policies, laws and standards. Data were collected through interview, questionnaire and documentary review. A sample of 52 respondents was purposively selected. The findings revealed that Micro and Macro appraisal were common methods used to appraise records; it was also observed that the organization lacked integration between archivists and records creators especially during appraisal process. Further, it was explored that no specific schedules, policies and standards used during appraisal process. Furthermore, it was discovered that the observed deficiencies affected proper appraisal of public records. The article recommends that, appropriate measures like training and technical supports should be taken by RAMD and government to improve appraisal of public records.
\end{abstract}

Key words: Records appraisal, Approaches, Archivist, Creator, Records value, Business activity

DOI: $10.7176 / \mathrm{IKM} / 9-5-04$

Publication date:May $31^{\text {st }} 2019$

\subsection{Introduction}

The core functions of archival institution are appraisal, selection, acquisition, preservation and provision of access to archives (William, 2006). On regard of records life cycle theory developed by T.R. Schellenberg in 1950s in United States of America, records pass through three stages; current stage, semi current stage and inactive stage. At inactive stage records are becoming archives, they need permanent preservation for future public use (Shephered, 2010). Records must be carefully determined by conducting records appraisal in order to select records of archival value.

Frank (2013) and Wojicik (2002) suggested some reasons on records appraisal that, the selected records will have permanent value for research purpose, appraisal frees space for active files, decreases the risk of misfiling and enhances efficiency in the process of records disposition, easily accessibility of records and making best use of space by maintaining maximum information having value and discarding un useful records. Cook (2010) contends that appraisal measures the value of records to determine important records to keep for construction of social memory. Kenosi and Moatlhodi (2012) added that appraisal will increase efficiency by saving space and controlling different risks like loss of files and duplications because of removing unnecessary records. They further argued that it will be easier to protect documents or records concerning clients' privacy and interest. Appraisal is the foundation for determining what records will be valuable to organization, how long will be retained to satisfy needs of clients or users, and what records will support the fulfillment of organizational vision and mission (ibid). Frank (2013) revealed that appraisal will put an organization free from buying unnecessary storage facilities to store unnecessary records. Kamatula (2013) assured that, appraisal supports performance of auditors and assessors by providing relevance information, organization will be at the position of identifying and protecting their vital records, and there are will be no illegal destruction of public records.

Scholars such as T.R Schellenberg in 1950s proposed two kinds of value or criteria known as Schellenberg's taxonomy of values; Primary value and Secondary value in determining what to preserve permanently and what to discard. The Schellenberg's taxonomy of values were explained by Shepherd and Yeo (2003) in details that, primary value is value primarily created to support organizational functions. Primary value counts on fiscal or financial, legal, operational or administrative value. Secondary value refers to adopted value after attaining or accomplishment of its primary value. It includes research, historical and evidential value though all records having both primary and secondary value contain evidence of particular activity or transactions done. In modern approach like macro appraisal, Schellenberg's taxonomy values basing on content were not agreed by other scholars like Terry cook who believed on evaluating business activity (Shephered and Yao, 2003). They believe 
on analysing context of a record. According to Cook (2000) in appraising any record, appraisal should base on analyzing organizational core business, functions, activities, transactions and systems. They evident the whole circumstances or purpose led to creation of such records. It becomes an endless debate.

In appraisal of records also various scholars lack common understanding or agreement on who should perform appraisal between records professionals and archival professionals. Theodore Schellenberg, Terry cook, Hellen Samuel believes on archivists to conduct selection and appraisal of records to retain research value. They were supported by Crag (2004) that Archivist is a specialist, a counselor who coaches and advising others on appraisal principles and procedures, determining which records are potential for organizational business. William (2006) added that archivist has to appraise records to ensure secondary value for research purpose. On the other hand, Hilary Jenkison was against on archivist to appraise records. Jenkison believed that appraisal must be carried out by those involved in creation process (creator) as well as their administrative use. Hilary Jenkison argued that archivists distort history and compromises impartially as archivists subjectively choose what to keep and what to discard. Nengomasha (2013) stressed that due to lack of common understanding on appraisal process and lack of knowledge on the field, it affected appraisal process in many countries across Sub Saharan Africa.

The article covers conceptualization of terms, appraisal theories and approaches, Tanzania legal requirement for appraisal, statement of the problem, objectives and research methodology. On the part of findings, the article reveals the useful appraisal approaches and procedures, what is to be appraised and who should conduct records appraisal, guiding tools for appraising records, challenges of appraisal and in Tanzania, conclusion and recommendation.

\section{Conceptualization of terms, appraisal theories and approaches}

\subsection{Archives}

Mckemmish (1993) defined archives as noncurrent records preserved because of their continuing value or permanent value. IRMT (1999) added that are records, usually but not necessarily noncurrent records, of enduring value selected for permanent preservation in archival repository. According to Franks (2013) Archives refer to the place dedicated to keep or preserve and use of archival materials or the division within an organization responsible for maintaining the organization's records of enduring value. Also the word archive refers to the organization, agency responsible for selection, care and use of the records of continuing value (ibid).

\subsection{Appraisal}

Scholars such as Shepherd and Yeo (2003); Ramos and Ortega (2006); William (2006); Smith (2007); Kenosi and Moatlhodi (2012); Frank (2013); defined appraisal as a process of evaluating records in order to select records having continuing value for preservation in archival centre or archival institution. Appraisal is the process by which archivist assesses the value of documents by determining institutional activities and decides which should be kept to provide a true image of society and which should be destroyed (ibid).

\subsection{Appraisal theories}

\subsubsection{Traditional theory (Micro appraisal approach)}

Is a traditional record-based, bottom-up appraisal theory proposed and discussed by Theodore Schellenberg and Hillary Jenkinson in 1950s. Kamatula (2013) and Niu (2012) contend that in this approach, the records are evaluated based on their values in two ways; folio by folio in one file or file by file. Kamatula (2013) states that the approach is applicable only in small sized organization creating and keeping only paper records. It is impractical in the modern environment where organizations are large in size, creating massive records electronically and manually and being geographically dispersed branches. Niu (2012) confirmed that micro appraisal is practical in small sized organization where few records are produced and not a complex organization creating large amount of records manually and electronically. Further, Shepherd and Yeo (2003) added that file by file review is impractical in electronic age. Basing on Hillary Jenkison's approach to trust administrators and creating agency, there is a possibility to destroy records having research and evidential value. This is because creators are interested on records supporting their day to day operations not secondary value. 


\subsubsection{Modern theories (Macro appraisal approach and functional analysis)}

According to Niu (2012) macro appraisal was developed in the early 1990s by Terry Cook. He proposed that appraisal should base on the organization's purpose, functions, structures, systems, of which should be analyzed first. Tschan (2002) supplemented that, the analysis of organizational functions, activities and transactions which constitute records creation is a part of macro appraisal. Helen Samuels believes that records exist to provide evidence of the functions and activities of an organization. Decision about the retention of records is based on the importance of the function. Cook (2000) added that in this approach, appraiser looks on records context and archivist is mandated to appraise records. Macro appraisal and functional analysis tend to downgrade the importance and content of records. It was asserted by Niu (2012) that, macro appraisal and functional analysis rejects value of records like research values because of assessing context instead of a record itself. It is directed towards key functions rather than records itself. Archivist is given mandate to appraise records basing on function and not creator who creates the records basing on functions of his or her organization. There for, it needs archives to study first functions of an organization to appraise. Shepherd and Yeo (2003) criticized that, it makes no provision for records managers' participation and archivists to look at records at all.

\subsection{The legal requirements for records appraisal in Tanzania}

The National Records and Archives Management Policy of 2011 provide some issues pertaining on appraisal and disposition of records. Policy issue No. 10 (disposition of records), the policy stipulates that, "the government should collaborate with public offices in developing and implementing retention and disposition schedules that will cover all public records regardless of their format; Public offices should ask the approval of Government before destructing or transferring records of enduring value to RAMD or any other place of deposit as prescribed by the retention and disposition schedule". Policy issue No.11 (acquisition and preservation of archives), the policy gives Government mandate to manage and preserve public and private records having national interest and making available for consultation.

The Records and Archives Management Act No 3 of 2002 , Part 3 mandates RAMD to accept the custody of semi current records in record centers from public offices, and manage public records having continuing value. The act mandates Director to authorize appraisal and disposition of records as provided by retention schedule. The Records and Archives Management Act No 3 of 2002 mandates Public offices to develop and implement Retention and Disposition Schedule under supervision of Director of RAMD; Transferring records to record centers except classified records having nature of National Security, Maintenance of public order, Safeguarding the revenue and protection of personal privacy. Public office must transfer classified records after attaining enduring value to custody of Director before exceeding 20 years. Also public offices must cooperate with Director on transferring records of continuing value from record centre to archives which were transferred as semi current records in regard of retention and disposition schedule.

The government decided to develop General records retention/disposal schedule in 2005 for effective appraisal. The schedule accommodates all records series created in public offices and time to retain as well as disposal action. The Records and Archives Management Regulations of 2007 supports the policy and Act by providing clear procedures on how to transfer records of enduring value, management of archives and procedures for records disposition like destruction.

Effective disposition depends on effective appraisal, there is no way RAMD can flight on implementing appraisal so as to meet legal requirement. Therefore, appraisal is a mandatory function.

\subsection{Statement of the problem}

Maseh and Mutula (2015) stipulated that records management policy; legal and regulatory frameworks require effective records management. One aspect of good records management is timely appraisal and disposal of records. In realizing the importance of records appraisal in the organization the RAMD was established and mandated with activities of appraising records for permanent preservation and timely destruction of records lacking value. Further, to give RAMD the authority and power of appraising records. The government of Tanzania decided to enact Records and Archives Management Act no.3 of 2002 which mandates RAMD to coordinate records management activities in public offices.

Despite the authority and power given to RAMD, studies reported that the Department has yet achieved its objective of establishment. The cases of backlogs and accumulation of records of different values have been 
observed in many public offices in Tanzania. This is confirmed by the findings of various studies such as RMT (2007); IRMT (2011); Kamatula (2010); Ndenje-Sichalwe (2010); Mohamed et al (2017). These studies reported the frequent cases of backlogs, inadequate space, accumulation of current, semi current and noncurrent records in records office and mis use of resources caused by ineffective appraisal. They further argued that some records are transferred to records centre and national archives while are not effectively appraised. Ineffective appraisal is a result of lacking clear procedures on what approach is correct to appraise records, what to be appraised on either value of records or business activities, and who has mandate to appraise record between creator of records and archivist.

The aim of this paper is to assess how the whole process of appraisal is conducted in Tanzania context in order to come up with common solution or suggestion on how appraisal should be performed.

\subsection{Aim of the study}

This article aimed at assessing on effectiveness of appraisal of public records in Tanzania

\subsection{Study objectives}

The study aimed to;

1. Explorer the approaches and procedures used to appraise records in Tanzania

2. Determine what does appraisal process involves (what is appraised and who is appraiser of records) in Tanzania.

3. Determine guiding tools for records appraisal in Tanzania

4. Analyze challenges facing appraisal process in Tanzania.

\section{METHODOLOGY}

The case study approach was employed for in-depth investigation of the problem at PO-RAMD because the department was mandated to coordinate records management activities and preservation of archives. Triangulation instrument was engaged by using interview for 6 respondents, questionnaire to 36 respondents, and in some extent supplemented by documentary review. Both qualitative and quantitative data collection were used in this study. Qualitative technique for data collection was employed through structured and unstructured interview method and quantitative techniques through questionnaires.

In this study the whole population of 52 was taken as a study sample. The selection of sample size for this study was based on Gay's guidelines (1996) which demands that for the population under 100 respondents, the whole population must be sampled. The whole population was selected as a study sample size. Data were collected from 42 respondents and 10 respondents did not respond on questionnaires. Therefore, the following were the distribution of the respondents; 1 Acting Director of record centre, 1 Acting Director National Archives, 2 Zonal officer in charge, 2 Record officers, 12 Records management assistants, 12 Senior records management assistants, 5 librarians, 4 technical officers and 3 Human resource officers.

\section{Findings and Discussion}

\subsection{Approach and procedures useful to appraise records}

For the context of Tanzania, only micro and macro approaches were researched. The findings show that both macro and micro appraisal approaches were used to appraise public records in public offices. The study revealed that; $20(55.6 \%)$ responded that both micro and macro were used at the same time, $10(27.8)$ responded on micro appraisal approach and $6(16.7 \%)$ responded on macro appraisal. Macro is applicable because MDA's, LGA's, ID's and other government institutions are large in size and create massive records in both paper and electronic form. Micro appraisal of file to file appraisal is applicable in small sized organization creating only paper records. One respondent insisted on micro appraisal that “... micro appraisal ensures authentic evaluation of a record value..." Basing on the nature of records kept by agencies, values of individual record is appraised and not functions. They believe that a file consists of records with different value hence passing through each folio is inevitable to reach a rational decision.

Through interview researcher asked respondents on procedures for appraisal process. The procedures vary between respondents. A common view amongst interviewees was that; Firstly, the formulation of appraisal team. The team should involve both archivists, records managers or officers and other stakeholders to balance interests of each group proposed; Secondly, after forming the team, there is a need to identify records to be appraised by 
considering principles of provenance and original order; Thirdly, respondent suggested on reviewing laws, policy and procedures available including retention and disposition schedule, appraisal and selection policy to consider principles of appraisal and retention period. Fourthly, determining storage accommodation available, condition and cost to preserve them where by wherever archival accommodation is inadequate acquisition can be suspended; Fifthly, Records value determination for future historical, evidential and research value, or retaining by evaluating business activities led to creation of such records; Sixthly, agreement to both sides (creating agency represented by records manager and archival institution represented by archivist); Seventhly, filling the appraisal forms and conducting appraisal. At the end of the process there was a sense of documenting the process amongst interviewees. Documentation plays a significant role for future evidential reference. Apart from procedures, factors such as records value, legal frameworks, cost, human resources, nature of records and time are mostly considered so as to conduct effective appraisal

Overall, these results indicate that both Micro and micro appraisal are useful methods of appraisal. Appraisal approach depends on nature and size of organization and records created. These findings may help us to understand where each method is applicable for effective appraisal. The findings is consistent with that of Kamatula (2013) who asserted that macro appraisal is practical in e records management era where many records are created, and micro is applicable in paper records and small sized organization.

\subsection{Understanding what does appraisal process involves (what is appraised and who is appraiser of records) in Tanzania context.}

The second objective was to determine who should undertake appraisal between creator and archivist, or both creator and archivist. Also what has to be appraised between records value (content) and business activity or functions (context) or both content and context. Findings indicate that all respondents 36(100\%) agreed that there must be cooperation of both creator and archivist during appraisal process.

One interviewee argued that; "...Creator is aware on the unique and specific functions which are not covered in general retention schedule, Archivist provides professional and technical assistant on appraisal mechanisms ..."

Then, 20(55.6\%) respondents identified that both records value and business activities are criteria for conducting appraisal, 14(38.9\%) respondents believe on appraising only record value, and 2(5.6\%) respondents revealed business activities as a criteria for conducting appraisal.

One respondent reported that; “...the value of records is resulted from Function, Activities and Transactions through day to day activities, for such fact once you evaluate value of records at the same time business activities are evaluated..."

For that reason, appraisal examines both value of records and business activity or functions from general/fond to specific or item itself. Both should be appraised for the purpose of being fair to both parent organization and public/national interest. These findings have important implications for developing the combination of creator and archivist. There is no way you can conduct records appraisal under separation of archivist and creator. These results reflect those of Crag (2004) who explored that, Creator knows the purpose of records he/she created and its value and vital records, whereas Archivists will be on the position of ensuring archival value or research values are put in consideration during appraisal. The combination of two entities is highly recommended because creator will be able to identify the records which still have value to the parent organization, and archivist will identify records with public/national interest (ibid).

\subsection{Guiding tools for records selection and appraisal}

This objective aimed to know what guiding tools were adhered when appraisal process is executed. Large number of respondents 33(91.7\%) assured that appraisal is guided by General Records Retention/Disposal Schedule of 2005, 28(77.8\%) Organizational records' checklist, 20(55.6\%) respondents, responded on the Records and Archives Management Act no 3 of 2002 and its Regulations of 2007 and National Records and Archives Management Policy of 2011. From the above findings, general retention/disposal schedule and checklist are most useful on conducting appraisal. Appraisal is guided by checklist, retention and disposal schedule which shows time to retain records and disposal action. Policies and legislations provide mandatory to RAMD for conducting effective appraisal and disposition of public records. Taken together, these results suggest that there is an association between legal frameworks and effective appraisal. There for, appraisal is guided by guidelines, legislations and policies for its effectiveness. The notion was supported by Maseh and Mutula (2015) 
that records management is a field which is guided by legal frameworks for good records management practices. Ndenje-Sichalwe (2010) asserted that good practices such as appraisal depend on policies and guidelines.

\subsection{Challenges associated with selection and appraisal}

Another objective was to explore challenges facing records appraisal, the table below reveals what are challenges face RAMD on the whole appraisal process.

Table 4.1: Challenges facing records appraisal in Tanzania $(\mathrm{N}=36)$

\begin{tabular}{|l|l|c|c|}
\hline $\mathbf{S} / \mathbf{N}$ & Challenge & Frequency. & Percent. \\
\hline $\mathbf{1}$ & $\begin{array}{l}\text { Lack of appraisal budget, cost sharing and } \\
\text { government support. }\end{array}$ & $\mathbf{2 8}$ & $\mathbf{7 7 . 8 \%}$ \\
\hline $\mathbf{2}$ & $\begin{array}{l}\text { Lack of creators optimum awareness and } \\
\text { technical skills }\end{array}$ & $\mathbf{2 8}$ & $\mathbf{7 2 . 2 \%}$ \\
\hline $\mathbf{3}$ & $\begin{array}{l}\text { Lack of clear legal frameworks on } \\
\text { appraisal }\end{array}$ & $\mathbf{2 6}$ & $\mathbf{6 3 . 9 \%}$ \\
\hline $\mathbf{4}$ & $\begin{array}{l}\text { There is rigidity among head of public } \\
\text { offices on appraisal }\end{array}$ & $\mathbf{2 0} \%$ \\
\hline $\mathbf{5}$ & $\begin{array}{l}\text { Biasness among archivists on what to } \\
\text { preserve and to discard. }\end{array}$ & $\mathbf{4 1 . 7 \%}$ \\
\hline $\mathbf{6}$ & $\begin{array}{l}\text { Lack of specific retention and disposal } \\
\text { schedule }\end{array}$ & $\mathbf{1 5}$ & $\mathbf{4 1 . 7 \%}$ \\
\hline $\mathbf{7}$ & $\begin{array}{l}\text { Non adherence of general retention } \\
\text { schedule of 2005 }\end{array}$ & \\
\hline
\end{tabular}

Source: Field Data 2018

Lack of appraisal budget and cost sharing among RAMD and public offices, Lack of awareness and technical skills were the main stipulated challenges. What is surprising is that, RAMD fails to conduct appraisal because of cost implications which does not resemble the planned budget. It becomes more challenging because public offices do not contribute on the cost, and the government is blind on any support. It is linked by lack of government and creators' optimum awareness and technical skills on appraisal. There is neither government nor creator can recognize appraisal merits in order to provide support. It was also reported by Ndenje-Sichalwe (2010) that there is lack of budget on records management in public offices which results to poor records management.

Contrary to expectations, there was rigidity among head of public offices on appraising public records to support the process. Also sometime biasness among creator and archivist affects the process hence results to ineffective appraisal. Respondents observed that appraisal fails to be implemented because public offices lack specific retention and disposal schedule. Contrary to expectations, it was discovered that, public offices does not adhere to General retention schedule developed by the government. The same notion was asserted by Kamatula (2010); Ndemanyisho (2014) that public offices lack their own policies and guidelines and does not adhere to the existing records management legal frameworks.

On the side of legal frameworks, they lack clear procedures on how appraisal decision must be conducted, whom to conduct appraisal of records. There is no specific approach on how to appraise semi current records in order to determine records having enduring value. Legal frameworks stipulate on how to transfer and disposing public records. Despite the fact that Records and Archives Management Act No.3 of 2002 requires establishment of Retention and disposal schedules, still there is lack of common understanding on regard of selection and appraisal process. Also there is no specific policies, guidelines and procedures on management of records including appraisal in some organizations. The use of checklist is an indicator of lacking specific retention and disposal schedule among public offices. Among the above challenges were also shared by Nengomasha (2013) in ESARBICA countries that records management practices is affected by lack of clear policies and regulations. Nengomasha (2013) added that some time people lacks knowledge and awareness on legislative requirement on proper management of records like timely appraisal and disposition, hence there is non-existent appraisal and disposition. 


\subsection{Conclusion}

The RAMD is aware on appraisal function as one of mandatory requirement. The department fails to execute appraisal effectively because of lacking awareness among public offices on appraisal process. They differ on procedures and approaches. There is also a problem of budget constraints to undertake appraisal. It is caused by poor government support and lack of cost sharing between RAMD and public offices.

Despite the fact that Records and Archives Management Act No. 3 of 2002 requires public offices to develop and implement specific retention and disposal schedules for effective appraisal and disposition, still not yet implemented. They use records check list to appraise records. Some of public offices are not aware on General retention/disposal schedule of 2005. These create rigidity among public offices to support RAMD to implement appraisal function. Currently, basing on organizational size and adoption of E government, effective appraisal is inevitable. Massive records are created in public offices. Effective appraisal and disposition saves organization space, it alleviates wastage of resource used to keep records having no value. As a final point, appraisal ensures selection of valuable records for permanent preservation that enhance evidential purpose, historical and research purpose as well as construction of social memory.

\subsection{Recommendation}

Appraisal process in Tanzania differs, The MDA'S, LGA'S, ID'S and other Government institutions have its own processes of appraising records. Therefore, the researcher recommends the following for the purpose of making successful appraisal of records;

To have uniformity in appraisal process regarding to ISO standards or Washington Archives. Allocation of enough budgets, raising awareness to both creator and archivist, accuracy should be administered in relation to retention schedule and appraisal policy.

There is a need to develop and implement specific retention and disposal schedule as described in the Records and Archives Management Act no. 3 of 2002. Records and Archives Management Department (RAMD) as mandated by the Records and Archives Management Act no.3 of 2002 to coordinate the whole process of records management in Tanzania must address the challenges associated with appraisal in MDA's, LGA's and ID's. RAMD must address the issue of updating Records management Policies, legal and regulatory frameworks. Legal frameworks should be reviewed to accommodate the new challenge of managing electronic records in Egovernment Paradigm and records appraisal. Together these result to answers of all questions associated with appraisal in Tanzania.

\section{REFERENCES}

Cook, T. (2010), Remembering the future; Appraisal of Records and the role of Archives in Constructing Social Memory, In Blown F.X. and Rosenberg, W.G. (eds) Archives, Documentation and Institutions of social memory, Essay from the Sawyer Seminar. USA: The University of Michigan Press

Cook, T. (2000) Appraisal Methodology: Macro-Appraisal and Functional Analysis. National Archives of Canada; Government Records Branch

Craig, B. (2004), Archival Appraisal Theory and Practice, Great Britain, K. G. Saur Verlag GmbH, Munchen

Franks, P. (2013), Records and Information Management. USA, American Library Association.

International Records Management Trust, (1999), Managing Archives, London: IRMT

International Records Management Trust.; (2007), Fostering Trusting and Transparency in Governance; investigating and addressing the Requirements for building integrity in public sector information systems in the ICT environment, London: IRMT

International Records Management Trust.; (2011), Managing records as reliable evidence for ICT/ eGovernment and Freedom of Information, London: IRMT

Johnson, S.E. (2008), Our Archives, Our Selves: Documentation Strategy and the Re-Appraisal of Professional Identity, the American Archivist, 71 (1):190-202

Kamatula, A.G. (2010), Managing records at the University of Dar es salaam, Tanzania. Master of Records and Archives Management Dissertation, University of Botswana, Gaborone

Kamatula, A.G. (2013). Theories, Principles and Practices in Records and Archives and Information Management, Moshi Tanzania, Stchi Simon

Kenosi, L. and Moatlhodi, T. (2012), The determination of value in archival science and the ever evolving theories of records selection, The Eastern Librarian, 23(1): 24-36. 
Maseh, E. and Mutula, S. (2015). Policy, Legal and Regulatory framework for Records management in the Kenyan Judiciary, ESARBICA Journal, 34 (2): 20-35

Mohamed, B; Rashel, A; Mwagike, R. (2017), Management of records in Tanzania: Review and appraisal of applicable theories and examination of selected empirical findings, Journal of Public Administration and Governance 8(1): 51-67.

Mckemmish, S. (1993), Introducing Archives and Archival Programs, In Ellis, J.(ed) Keeping Archives, pp 1-24 D.W Thorpe 18 salmon street port Melbourne, Victoria Austria. Australian Society of Archivists

Ndemanyisho, A. J. (2014), Reflecting on revenue collection in Tanzania: What went wrong with records? International Journal of Education and research, 2(8): 101-110

Ndenje-Sichalwe, E. N. (2010), The significance of Records management to fostering accountability in the public service reform programme of Tanzania, Ph.D Thesis. University of KwaZulu-Natal; South Africa

Nengomasha, T. (2013), The past, present and future of records and archives management in sub-Saharan Africa, Journal of the South African Society of Archivists, 46(2):2-11

Niu, J. (2012), Appraisal and custody of electronic records: findings from four national archives, Archival Issues, 34 (2): $117-130$

Shepherd, E. and Yeo, G. (2003) Managing Records: A Handbook of Principles and Practice. London and Neil Schuman Publishers, Inc., New York

Shehered, E. (2010), Archival science, Encyclopedia of Library and Information Sciences, Third Edition 1:1, 179-191

Smith, K. (2007) Public sector records management; A practical guide: Methods, Brighton England, Aldeshort

Tschan, R. (2002), A Comparison of Jenkinson and Schellenberg on Appraisal, the American Archivist, 65, (2): 176-195.

Williams, C. (2006) Managing archives: foundations, principles and practice. Hart court: Chandos Publishing (Oxford) Limited.

Wojicik, C. (2002), Appraisal, reappraisal, and de accessioning, Archival Issues, 27 (2): 151-160 